\title{
EFFECTS OF ANTHROPOGENIC LAND USE ON ODONATA IN PLAYAS OF THE SOUTHERN HIGH PLAINS
}

\author{
K.M. Hernandez ${ }^{1,2,3}$, B.A. Reece ${ }^{2}$, and N.E. McIntyre ${ }^{2,4}$
}

\begin{abstract}
Playas are ephemeral wetlands that are the only source of aboveground freshwater in the southern Great Plains, making them of vital importance to aquatic and amphibious animals. Playas are also highly threatened from anthropogenic land use (chiefly agriculture, which decreases hydroperiod through increased sedimentation). We examined community structure of adult odonates (dragonflies and damselflies) in playas differing in the 2 main regional forms of surrounding land use (cropland vs. grassland). Analysis of odonate diversity revealed high overlap between cropland and grassland playas. Traditional species-area theory did not fit observed patterns, as there appears to be a threshold playa size that supports maximal odonate diversity; this nonlinear response may reflect a tradeoff between hydroperiod and availability of emergent vegetation that is required for perching and oviposition. Since agriculture effectively reduces playa depth but not size of the overall playa watershed, this may mean that cropland playas serve as "ecological traps." This property has important implications for regional odonate diversity.
\end{abstract}

Key words: Odonata, playa, species-area relationship, anthropogenic land use.

Playas are shallow, temporary wetlands of the Great Plains of North America. There are approximately 30,000 such wetlands, with most $(\sim 83 \%)$ occurring in west Texas at a density of 1 per $2.5 \mathrm{~km}^{2}$ (Guthery et al. 1981). Created from runoff, playas average 6.3 ha in area $(\sim 80 \%$ are $<12 \mathrm{ha}$ ) and $1 \mathrm{~m}$ in depth (Guthery et al. 1981, Gustavson et al. 1994, Smith 2003). Playas represent the only source of aboveground freshwater in the southernmost portion of the Great Plains (termed the Southern High Plains or SHP; Fig. 1), a semiarid region $\sim 104,000 \mathrm{~km}^{2}$ in size. The SHP lacks permanently flowing watercourses and averages only $\sim 40 \mathrm{~cm}$ of precipitation annually, occurring mostly from April through September. Playas are thus quite literally oases for wildlife in this region (Smith 2003).

Playas are also being impacted by human activities, particularly agriculture. The Southern High Plains is one of the most intensively cultivated areas of the world. Cropland accounts for $46 \%$ of the land surface area of the SHP (Haukos and Smith 1994). Former cropland that has been reclaimed as grassland through the USDA Conservation Reserve Program accounts for an additional $12 \%$, and indigenous grassland comprises 37\% (Haukos and Smith 1994).
Agriculture increases sedimentation of playas, which alters hydroperiod; playas surrounded by cropland have 8.5 times the amount of sediments as playas within a grassland context (Luo et al. 1997). Cropland playas are therefore shallower and susceptible to more rapid drying than playas within grassland watersheds. In addition, cropland playas are also subject to chemical inputs from pesticides, fertilizers, and so forth (Thurman et al. 2000). For aquatic or amphibious organisms, the form of land cover surrounding a playa may thus dictate survivorship or successful reproduction.

Odonates (Odonata: dragonflies and damselflies) are the most conspicuous and abundant predators in playas (because of their ephemeral nature, playas are naturally fishless). Over 50 species occur in the SHP (Abbott 2001, Abbott et al. 2003). Adults fly, but nymphs are aquatic. Eggs are laid endophytically, just under the water surface, or within damp sediments. The eggs may overwinter, withstanding several months of desiccation (through diapause), or hatch 2-4 weeks after being laid if the weather is still warm and the playa is still wet. Most dragonfly species on the SHP are univoltine, whereas many damselflies are bivoltine (personal observation). Most eggs hatch in spring

\footnotetext{
${ }^{1}$ Howard Hughes Medical Institute, Texas Tech University, Lubbock, TX 79409-3131.

${ }^{2}$ Department of Biological Sciences, Texas Tech University, Lubbock, TX 79409-3131.

3Present address: Department of Biological Sciences, Purdue University, 915 W. State St., West Lafayette, IN 47907.

${ }^{4}$ Corresponding author. E-mail: nancy.mcintyre@ttu.edu
} 


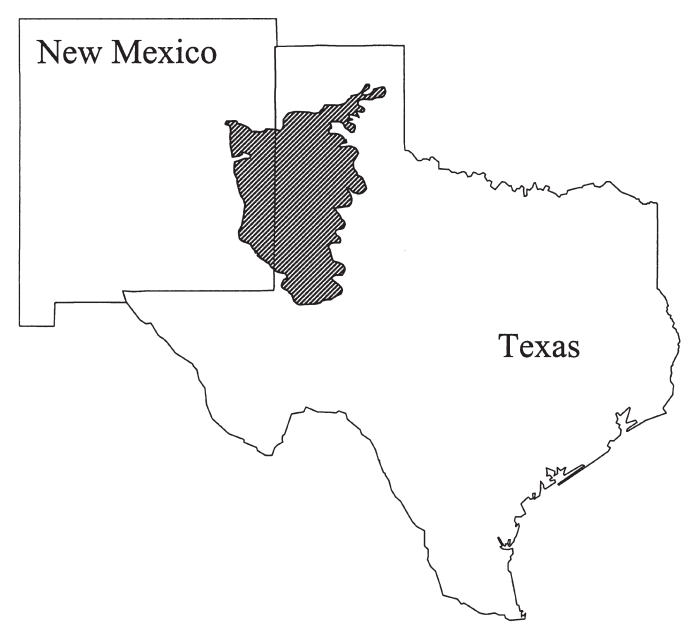

Fig. 1. Location of the Southern High Plains (shaded area). Based on Choate (1997).

or summer following rain and playa refill. The nymphs are predaceous and must complete their development before a playa dries. The nymphs molt through several instars over a period of 2-6 weeks. Adults emerge from late spring through late summer. Newly emerged adults (called tenerals) then complete their sexual maturation over 1-5 days. Few studies have quantified dispersal rates and distances in odonates, and our study did not measure adult dispersal at playas. However, according to existing literature, most adult odonates spend their lives within $100 \mathrm{~m}$ of their natal site (Schutte et al. 1997, Corbet 1999 and references therein), although a few individuals may disperse 1-3 km away (Moore 1954, Cordero 1995, Schutte et al. 1997) and some migratory species may move over hundreds of kilometers (e.g., Russell et al. 1998). Settlement at a playa and oviposition are thought to be triggered by the presence of littoral vegetation (Westfall and May 1996). Adults are sexually dimorphic and readily identifiable to species in the field, and both adults and nymphs are abundant and relatively easy to capture (Gribbin and Thompson 1991, Fincke 1992, Cordero 1995, Schutte et al. 1997, Thompson 1997). Odonates thus provide a tractable model system for examining effects of anthropogenic land use on community structure of playa wildlife. Because sedimentation decreases playa hydroperiod, we hypothesized that there would be fewer odonate species and individuals in cropland playas than in grassland playas.
Because playas vary considerably in size, ranging from 0.12 ha to 341 ha (Guthery et al. 1981, Gustavson et al. 1994, Smith 2003), a theoretical framework with which to understand the influence of playas on biota might be obtained from the species-area relationship. As perhaps the most well-documented pattern in all of ecology, the species-area relationship is formalized as $S=k A^{z}$ (linearized as $\log [S]$ $=\log [k]+z \log [A])$, where $S$ is species richness, $A$ is area, $k$ is a constant that represents the intercept, and $z$ is a power exponent (i.e., the slope of the log-transformed species vs. area plot; Preston 1962). The power exponent usually falls between 0.15 and 0.39 (May 1975) and can be used as an indicator of an area's tendency to experience species losses; higher values occur on smaller or more isolated areas than on larger or contiguous ones (MacArthur and Wilson 1967). We hypothesized that the speciesarea relationship would thus be steeper for cropland than grassland playas (i.e., $z_{\text {cropland }}$ $\left.>z_{\text {grassland }}\right)$. A positive association between playa area and species richness has been documented for plants (Smith and Haukos 2002) and birds (J.-S. Tsai unpublished data) in this region, and wetland area has been shown to be positively associated with odonate richness in Switzerland (Oertli et al. 2002) and Japan (Kadoya et al. 2004). Therefore, we hypothesized that there would be a positive speciesarea relationship for playa odonates.

\section{Methods}

We sampled adult odonates at a total of 80 playas from June through September in 2003 and 2004 (20 cropland and 20 grassland playas each year, for a total of 40 playas sampled each year; different playas were sampled in each year, for a total of 80 playas surveyed; Fig. 2). Odonates were encountered at 29 cropland and 32 grassland playas. Most playas were visited twice (range 1-5 visits), with visits separated by 14-21 days. Two independent datasets were obtained during this time. The 1st and larger dataset consisted of adults that were collected and identified to species during both 2003 and 2004. Voucher specimens are housed in the Department of Biological Sciences at Texas Tech University. The 2nd dataset was designed to supplement these collections by including observations of adults in addition to collections at playas in 2004. Only if species could 


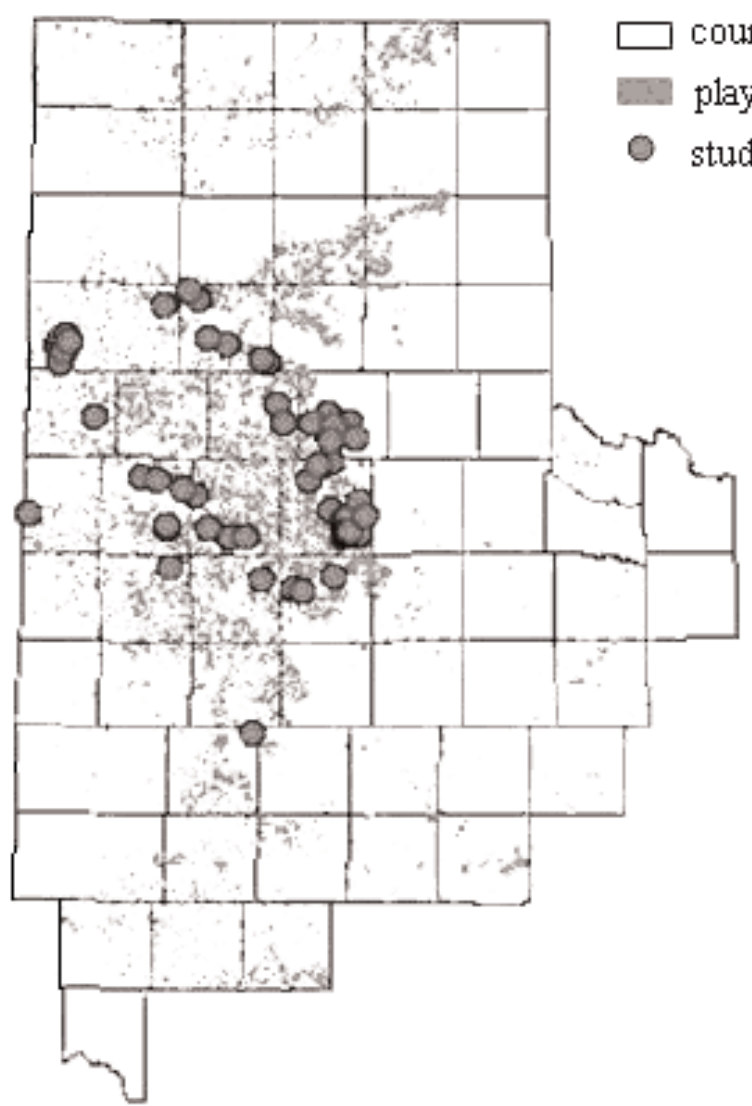

cunty boundaries

playas

study playas

Fig. 2. Distribution of playas (including the 80 study playas) within the Southern High Plains of Texas. Base layer from the Playa Lakes Digital Database, Texas Tech University (Fish et al. 1998).

be confidently identified were observations included for analysis. All species included in the observational dataset were also present in the collected dataset. These data represent species presence or absence and not abundance, which is notoriously difficult to assess for odonates (Corbet 1999).

The area of each playa was determined by Fish et al. (1998), who measured the surface area of each playa basin using aerial photographs digitized into a geographic information systems (GIS) coverage. Playas can be distinguished from surrounding areas by the presence of a unique soil type, Randall clay, which delimits a closed watershed (Luo et al. 1997). Playa watersheds are distinctive even when dry because of a characteristic vegetative community in this soil (Haukos and Smith 1997). We used a static measurement (watershed size) rather than a highly variable measurement (water volume) to denote playa area because the amount of water contained within a playa varies day by day (and even hour by hour) with rainfall and evaporation. However, because odonate eggs and larvae can withstand periods of desiccation, this variability should not affect the potential number of species or individuals present within a watershed of a given size. Using watershed size rather than amount of water contained within a playa is thus a more accurate measure of habitat area. Sedimentation of cropland playas affects water volume but not watershed size, meaning that our use of watershed size as a measurement of area may be so conservative as to dampen potential distinctions between cropland and grassland playas. However, water volume is so highly variable that making unbiased comparisons with it is impossible.

Effects of playa area and surrounding landuse types on mean richness were assessed by 1-way analysis of variance (ANOVA). Log-transformed species richness was plotted against $\log ($ playa area $)$ on a $\log -\log$ plot $(\log [S]$ vs. 
$\log [A])$, with slopes examined by regression analysis. Values of $\log (S)=0$ (i.e., only 1 species encountered) were omitted from slope analysis; this removed 6 cropland and 11 grassland playas from analysis.

\section{RESULTS}

We encountered 22 species of odonates, 16 of which occurred at both cropland and grassland playas (Table 1). We hypothesized that there would be fewer species in cropland playas than grassland playas. Contrary to expectations, however, we found no such difference: the average number of species (ANOVA: $F_{1}=$ $0.09, P=0.7650)$ did not differ with the type of land use surrounding a playa.

We hypothesized that there would be a positive species-area relationship for playa odonates. However, neither ANOVA nor regression provided support. A nonlinear response was observed for both cropland and grassland playas (Fig. 3: raw data; Fig. 4: log-log plot). The shapes of the log-log plots for cropland playas (2nd-order polynomial nonlinear regression: $\left.\mathrm{R}^{2}=0.0254, \mathrm{P}=0.0379\right)$ and grassland playas (2nd-order polynomial nonlinear regression: $\mathrm{R}^{2}=0.0265, P=0.0070$ ) were significantly nonlinear. This was also the case when both were considered collectively $\left(\mathrm{R}^{2}=0.0247\right.$, $P=0.0476$ ). Linear regression (the classic species-area response) provided less explanatory power in both cases even though the data were log-transformed, which typically increases linearity (cropland: $\mathrm{R}^{2}=0.0003193, P=0.9117$; grassland: $\mathrm{R}^{2}=0.004318, P=0.6992$; both: $\left.\mathrm{R}^{2}=0.00008638, P=0.9356\right)$. The nonlinear response revealed maximum richness at playas 〜8-18 ha in size; playas larger than this threshold did not support more species.

We hypothesized that cropland playas would exhibit a steeper slope than grassland playas. Because the relationships were not linear, this hypothesis could not be tested per se.

\section{Discussion}

A wide range of species richness values existed for the range of playa areas. The traditional (linear) species-area relationship did not hold for playa odonates (i.e., a steady increase in richness with playa area was not observed). Instead, a threshold response to playa area was detected, evidenced by a nonlinear speciesarea relationship (with maximum richness at
TABLE 1. Odonata species (Suborder Anisoptera: dragonflies; Zygoptera: damselflies) by playa type. A number indicates presence (proportion of playas where that species was encountered); an " $\mathrm{X}$ " indicates that the species was observed in at least 1 playa but that proportional data were not collected; a dash indicates absence.

\begin{tabular}{lcc}
\hline Species & Cropland & Grassland \\
\hline ANISOPTERA & & \\
Anax junius & 0.1875 & 0.1818 \\
Erythemis simplicicollis & 0.0313 & $\mathrm{X}$ \\
Erythemis vesiculosa & - & 0.0303 \\
Erythrodiplax umbrata & - & 0.0303 \\
Libellula pulchella & 0.0313 & 0.0606 \\
Libellula saturata & 0.0313 & 0.0606 \\
Orthemis ferruginea & 0.0313 & $\mathrm{X}$ \\
Pachydiplax longipennis & $\mathrm{X}$ & 0.0303 \\
Pantala flavescens & 0.1563 & 0.0606 \\
Pantala hymenaea & 0.1875 & 0.0303 \\
Perithemis tenera & 0.0625 & 0.0303 \\
Plathemis lydia & 0.0313 & 0.0303 \\
Plathemis subornata & - & 0.0303 \\
Rhionaeschna multicolor & 0.0313 & - \\
Sympetrum corruptum & 0.4688 & 0.6970 \\
Tramea lacerata & 0.1563 & 0.0606 \\
Tramea onusta & 0.3125 & 0.2121 \\
ZyGOPTERA & & \\
Enallagma civile & 0.8438 & 0.5758 \\
Ischnura demorsa & - & 0.0303 \\
Ischnura denticollis & 0.0313 & - \\
Ischnura hastata & 0.0625 & 0.0303 \\
Lestes disjunctus & 0.2500 & 0.3333 \\
\hline
\end{tabular}

playas $\sim 8-18$ ha in size). This nonlinear pattern may exist because a larger playa is also a deeper playa, and playas that are very deep do not support as much emergent vegetation as do shallow playas (Smith and Haukos 2002). Emergent vegetation is used by many species of odonates for perching and oviposition and is considered a key habitat element for the presence of many (although not all) species (Westfall and May 1996). At some threshold size, then, having a larger perimeter does not compensate for loss of effective habitat area in the playa center. Because sedimentation decreases playa depth, however, this threshold effect is not as strong in cropland as in grassland playas, and may explain the lack of significance in the cropland species-area relationship or lack of differences in diversity. Because agricultural sedimentation effectively reduces playa depth (allowing plant growth), a situation is created whereby the greater emergent vegetation available at a cropland playa may provide a false signal relative to a grassland playa of quality 

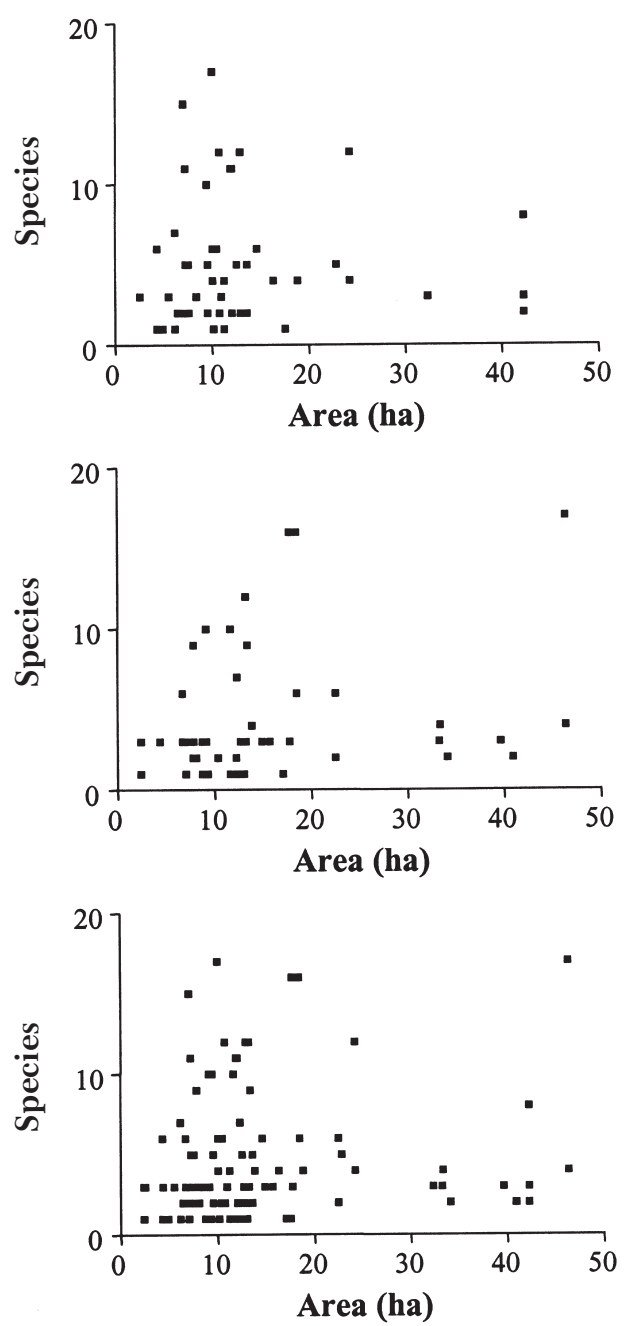

Fig. 3. Species-area relationships (untransformed data) for cropland (top), grassland (middle), and both (bottom) playas.

habitat to an adult seeking a territory or oviposition site (i.e., a cropland playa may serve as an "ecological trap" sensu Gates and Gysel 1978).

Nonlinear species-area relationships have also been documented for a few other taxa (e.g., birds of the Solomon Islands [Diamond and Mayr 1976]; stream macroinvertebrates, [Stewart et al. 2003]) and have been attributed to rapid turnover in small habitat patches (areas too small to support a species, leading to rapid extinction and turnover). Thus, the presence of odonates at playas should not be construed to mean that some minimum area requirement
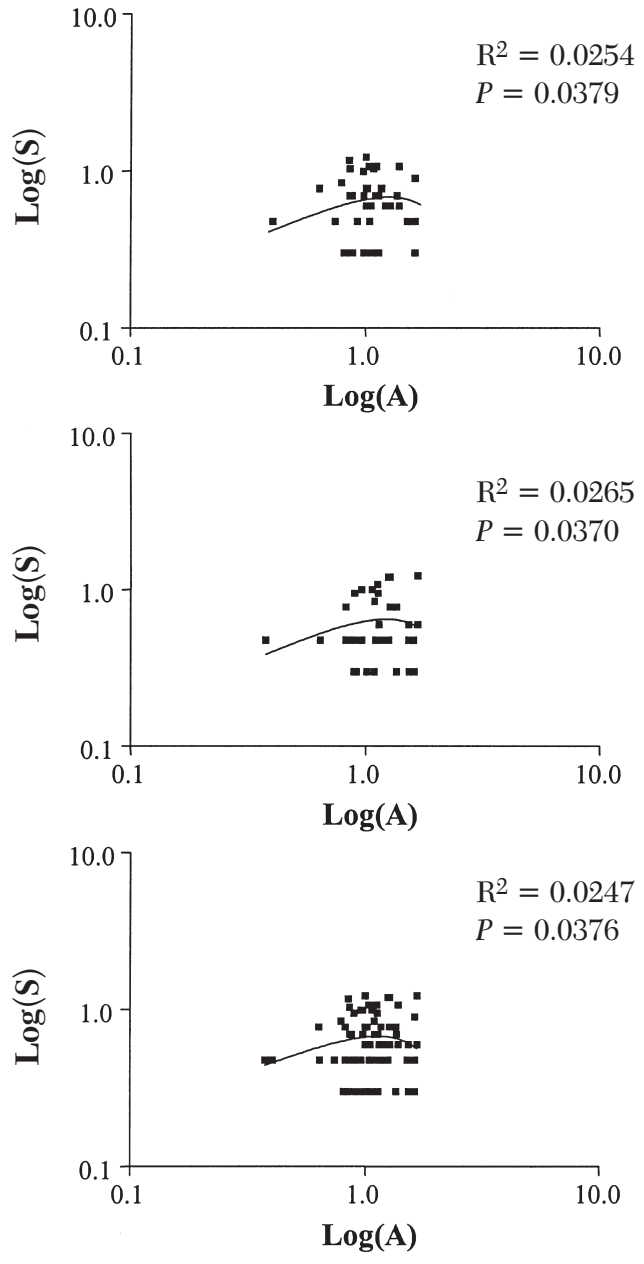

Fig. 4. Species-area relationships (log-transformed) for cropland (top), grassland (middle), and both (bottom) playas. Lines are significant nonlinear regression lines.

is being met. In addition, the relatively low $\mathrm{R}^{2}$ values we obtained indicate that other factors, in addition to playa area, are dictating odonate community structure. The occurrence of adult odonates is no guarantee of successful reproduction and larval development. Future studies should endeavor to identify the main factors governing odonate presence at playas.

\section{ACKNOWLEDGMENTS}

This research was supported in part by a Howard Hughes Medical Institute grant to Texas Tech University (TTU) through the Undergraduate Biological Sciences Education Program. Additional support was provided by C.F. 
Martin (Department of Mathematics and Statistics, TTU) and L.M. Smith (Department of Range, Wildlife, and Fisheries Management, TTU) and a TTU Chancellor's Fellowship to B.A.R. We thank J.-S. Tsai for field assistance and numerous landowners for access to their property. R.E. Strauss (Department of Biological Sciences, TTU) provided statistical advice. Comments from D. Paulson and an anonymous reviewer improved the manuscript.

\section{Literature Cited}

Аввотт, J.C. 2001. Distribution of dragonflies and damselflies (Odonata) in Texas. Transactions of the American Entomological Society 127:199-228.

Aвbott, J.C., R.A. Behrstock, And R.R. Larsen. 2003. Notes on the distribution of Odonata in the Texas Panhandle, with a summary of new state and county records. Southwestern Naturalist 48:444-448.

Choate, L.L. 1997. The mammals of the Llano Estacado. Special Publications of the Museum of Texas Tech University, Number 40, Lubbock.

Conbet, P.S. 1999. Dragonflies: behavior and ecology of Odonata. Cornell University Press, Ithaca, NY.

Cordero, A. 1995. Correlates of male mating success in two natural populations of the damselfly Ischnura graellsii (Odonata: Coenagrionidae). Ecological Entomology 20:213-222.

Diamond, J.M., AND E. Mayr. 1976. Species-area relations for birds of the Solomon archipelago. Proceedings of the National Academy of Sciences 73:262266.

FInCKE, O.M. 1992. Consequences of larval ecology for territoriality and reproductive success of a Neotropical damselfly. Ecology 73:449-462.

Fish, E.B., E.L. Atkinson, T.R. Mollhagen, C.H. Shanks, and C.M. Brenton. 1998. Playa lakes digital database for the Texas portion of the Playa Lakes Joint Venture Region. Main Library Map Collection, Texas Tech University, Lubbock.

Gates, J.E., AND L.W. Gysel. 1978. Avian nest dispersion and fledging success in field-forest ecotones. Ecology 59:871-883.

Gribiin, S.D., And D.J. Thompson. 1997. The effects of size and residency on territorial disputes and shortterm mating success in the damselfly Pyrrhosoma nymphula (Sulzer) (Zygoptera: Coenagrionidae). Animal Behavior 41:689-695.

Gustavson, T.C., V.T. Holliday, and S.D. Hovorka. 1994. Development of playa basins, Southern High Plains, Texas and New Mexico. Pages 5-14 in L.V. Urban and A.W. Wyatt, editors, Proceedings of the Playa Basin Symposium. Water Resources Center, Texas Tech University, Lubbock.

Guthery, F.S., F.C. Bryant, B. Kramer, A. Stoecker, and M. Dvorack. 1981. Playa assessment study. U.S.
Water and Power Resources Service, Southwest Region, Amarillo, TX.

Haukos, D.A., AND L.M. Smith. 1994. The importance of playa wetlands to biodiversity of the Southern High Plains. Landscape and Urban Planning 28:83-98.

1997. Common flora of the playa lakes. Texas Tech University Press, Lubbock.

Kadoya, T., S.-I. Suda, and I. Washitani. 2004. Dragonfly species richness on man-made ponds: effects of pond size and pond age on newly established assemblages. Ecological Research 19:461-467.

Luo, H.R., L.M. Smith, B.L. Allen, and D.A. Haukos. 1997. Effects of sedimentation on playa wetland volume. Ecological Applications 7:247-252.

MacArthur, R.H., and E.O. Wilson. 1967. The theory of island biogeography. Princeton University Press, Princeton, NJ.

MAY, R.M. 1975. Patterns of species abundance and diversity. Pages 81-120 in M.L. Cody and J.M. Diamond, editors, Ecology and evolution of communities. Harvard University Press, Cambridge, MA.

Moore, N.W. 1954. On the dispersal of Odonata. Proceedings of the Bristol Naturalists' Society 28:407-417.

Oertli, B., D.A. Joye, E. Castella, R. Juge, D. Cambin, and J.-B. Lachavanne. 2002. Does size matter? The relationship between pond area and biodiversity. Biological Conservation 104:59-70.

Preston, F.W. 1962. The canonical distribution of commonness and rarity of species. Ecology 43:185-215.

Russell, R.W., M.L. May, K.L. Soltesz, and J.W. FitzPATRICK. 1998. Massive swarm migrations of dragonflies (Odonata) in eastern North America. American Midland Naturalist 140:325-342.

Schutte, G., M. Reich, and H. Plachter. 1997. Mobility of the rheobiont damselfly Calopteryx splendens (Harris) in fragmented habitats (Zygoptera: Calopterygidae). Odonatologica 26:317-327.

Smith, L.M. 2003. Playas of the Great Plains. University of Texas Press, Austin.

Smith, L.M., AND D.A. Haukos. 2002. Floral diversity in relation to playa wetland area and watershed disturbance. Conservation Biology 165:964-974.

Stewart, T.W., T.L. Shumaker, and T.A. Radio. 2003. Linear and nonlinear effects of habitat structure on composition and abundance in the macroinvertebrate community of a large river. American Midland Naturalist 149:293-305.

Thompson, D.J. 1997. Lifetime reproductive success, weather and fitness in dragonflies. Odonatologica 26:89-94.

Thurman, E.M., K.C. Bastian, and T. Mollhagen. 2000. Occurrence of cotton herbicides and insecticides in playa lakes of the High Plains of West Texas. Science of the Total Environment 248:189-200.

Westfall, M.J., and M.L. May. 1996. Damselflies of North America. Scientific Publishers, Gainesville, FL.

Received 1 June 2005 Accepted 30 August 2005 